\title{
The management of lens damage in perforating corneal lacerations
}

\author{
RENÉ MUGA AND EUGENIO MAUL \\ From the Department of Ophthalmology, Dr Alejandro del Rio General Emergency Hospital of \\ Metropolitan Santiago, and from the Department of Ophthalmology, Universidad Católica, \\ Medical School, Santiago, Chile
}

SUMMARY Lens damage is present in $30 \%$ of perforating injuries of the anterior segment of the eye. There is no consensus on whether the cataractous lens should be removed at the initial repair of the corneal laceration or later, when the eye has recovered from injury. Twenty-seven consecutive cases with a perforating corneal injury and lens damage were alternatively treated either with simultaneous corneal suturing and cataract removal or with corneal suturing and delayed cataract removal several weeks later. The difference in the frequency of complications between the 2 groups was significant. The 1-step procedure was technically easier to perform, the period of postoperative irritation was shorter, complications due to the presence of an injured lens were prevented, and visual rehabilitation occurred earlier.

Lens damage is present in $30 \%$ of perforating ocular lacerations (Roper-Hall, 1959; Muga, 1975; Adhikary et al., 1976). There are 2 ways of managing these cases: the immediate repair of the corneal laceration, leaving the cataract for a second operation as a separate problem; or the simultaneous corneal repair and extraction of the cataract. Some authors think that the cataract should be removed during the initial operation (Barraquer, 1975; Haik and Coles, 1972); others may prefer to wait and treat the cataract at a later stage after primary repair of the penetrating wound (Reinecke and Beyer, 1966; Havener and Gloeokner, 1969; Duke-Elder, 1972).

The purpose of this paper is to report our experience with the management of lens injury coexisting with perforating lacerations of the anterior segment of the eye.

\section{Materials and methods}

Between March and December 1976, 129 perforating injuries of the anterior segment were admitted to the Ophthalmology Service of the Dr Alejandro del Río General Emergency Hospital in Santiago, Chile. Thirty-eight cases had lens damage at slitlamp examination. In 27 patients lens damage

Address for reprints: Dr Eugenio Maul, Casilla 19, Santiago 10, Chile presented as a disruption of the capsule with or without herniation of some lens substance, but the lens maintained its body and normal location. These patients were consecutively and alternately included in 2 series. In one series the damaged lens was aspirated simultaneously with the wound repair and in the other series aspiration of the lens was deferred for a second operation. Eleven cases presented with a completely disrupted lens, with flocculent lens material dispersed in the anterior chamber or outside the wound. In 2 of these 11 cases the lens could not be identified. These patients presented also severe damage to posterior segment structures, vitreous and ciliary body. Lens material was eliminated during the anterior chamber toilet at first surgery. Only in 2 cases was the state of the lens not clear at first examination due to the presence of fibrin or exudate in front of the pupil. These cases were operated on for repair of the corneal wound and observed for lens damage. These last 2 groups were not included in the evaluation of the 2 series.

The results of the 2 series were analysed comparing the following parameters: anterior chamber activity, iris synechiae to the wound or the lens remnants, fibrous strands in the anterior segment, anterior chamber depth, and complications. Final vision was not considered to evaluate the 2 series, since many effects of ocular trauma other than lens damage influence the final results. However, it will be presented in the tables. 
Table 1 Simultaneous aspiration of the lens and corneal wound repair

\begin{tabular}{|c|c|c|c|c|c|c|c|}
\hline \multirow[b]{2}{*}{$\begin{array}{l}\text { Case } \\
\text { no. }\end{array}$} & \multirow[b]{2}{*}{ Age (years) } & \multirow{2}{*}{$\begin{array}{l}\text { Interval injury to } \\
\text { operation (hours) }\end{array}$} & \multicolumn{5}{|c|}{ Postoperative evaluation } \\
\hline & & & $\begin{array}{l}\text { Anterior } \\
\text { chamber }\end{array}$ & Sinechiae & $\begin{array}{l}\text { Ocular irritation } \\
\text { (days) }\end{array}$ & Complications & Vision \\
\hline 1 & 7 & 4 & Flat & None & 3 & Pupillary block & $20 / 70$ \\
\hline 2 & 13 & 2 & Deep & None & 4 & Lens remnants & $20 / 50$ \\
\hline 3 & 14 & 4 & Deep & None & 5 & None & NLP \\
\hline 4 & 27 & 12 & Deep & + & 4 & None & HM \\
\hline 5 & 13 & 19 & Deep & None & 4 & None & $20 / 70$ \\
\hline 6 & 7 & 2 & Deep & None & 5 & Hyphaema & $20 / 100$ \\
\hline 7 & 4 & 7 & Deep & None & 4 & None & - \\
\hline 8 & 15 & 48 & Deep & None & 9 & None & $20 / 30$ \\
\hline 9 & 19 & 42 & Deep & None & 5 & None & $20 / 70$ \\
\hline 10 & 27 & 4 & Deep & None & 4 & None & $20 / 70$ \\
\hline 11 & 21 & 4 & Deep & None & 5 & None & $20 / 25$ \\
\hline 12 & 28 & 6 & Deep & None & 6 & None & $20 / 50$ \\
\hline
\end{tabular}

SURGICAL TECHNIQUE

The corneal laceration was repaired as previously described (Maul and Muga, 1977). When the injured lens was removed at the initial operation, it was aspirated and irrigated through two limbal keratotomies, not through the wound. Two 20-gauge cannulas were used, 1 connected to the anterior chamber with a Ringer's solution reservoir and the other connected to the anterior chamber with a vacuum pump. The anterior chamber depth was maintained with saline perfusion during the operation. In the other series at initial surgery the wound was sutured and the anterior chamber reformed. Six weeks later the patients were rescheduled for cataract surgery. An aspiration and irrigation technique as described was used. In both series a peripheral iridectomy was performed and the anterior chamber was reformed with saline and air and swept with a cyclodialysis spatula for prevention of sinechiae.

\section{Results}

In Table 1 the results of simultaneous aspiration of the lens and repair of the corneal laceration in 12 patients is presented. In 15 cases aspiration of the lens was programmed to be done 6 weeks later. However, in 10 of these lens surgery had to be performed earlier. In Table 2 the features of these 10 cases are given. Between 1 and 8 days from the first operation of these cases the cataract became intumescent and an immediate removal was necessary. This is a high percentage of early emergency reoperations and does not agree with a waiting period of 3 to 4 weeks. In Table 3 the features of 5 cases where surgery was done 6 weeks after primary repair are presented. All patients received systemic antibiotics. Atropine $1 \%$ and antibiotic-steroid eyedrops were administered in the conjunctival cul-de-sac.

Aspiration of disrupted lens at initial repair in our series offered the following advantages: lens substance was easily aspirated, transparency of the freshly lacerated cornea allowed good observation of anterior segment structures, and manipulation of tissues was easy to control. Mixture of lens material and vitreous was avoided, which if associated with hyphaema may turn the situation even worse (Coles and Haik, 1972; Hutton et al., 1976). Postoperative anterior chamber activity was shorter. In cases where lens aspiration was done 6 weeks after primary repair of the corneal injury the following difficulties were encountered. Hardening of lens capsule and partially reabsorpted lens substance made its removal difficult. Synechiae of iris to the site of capsular disruption were always present. Vascularisation of lens substance and fibrous strands between anterior chamber structures were also a common finding. All these features determined a difficult and prolonged operation. Extraction of the lens could not be always completed, and hyphaema was a common complication.

\section{Discussion}

Simultaneous repair of a perforating injury of the 
Table 2 Corneal wound repair and early aspiration of the lens

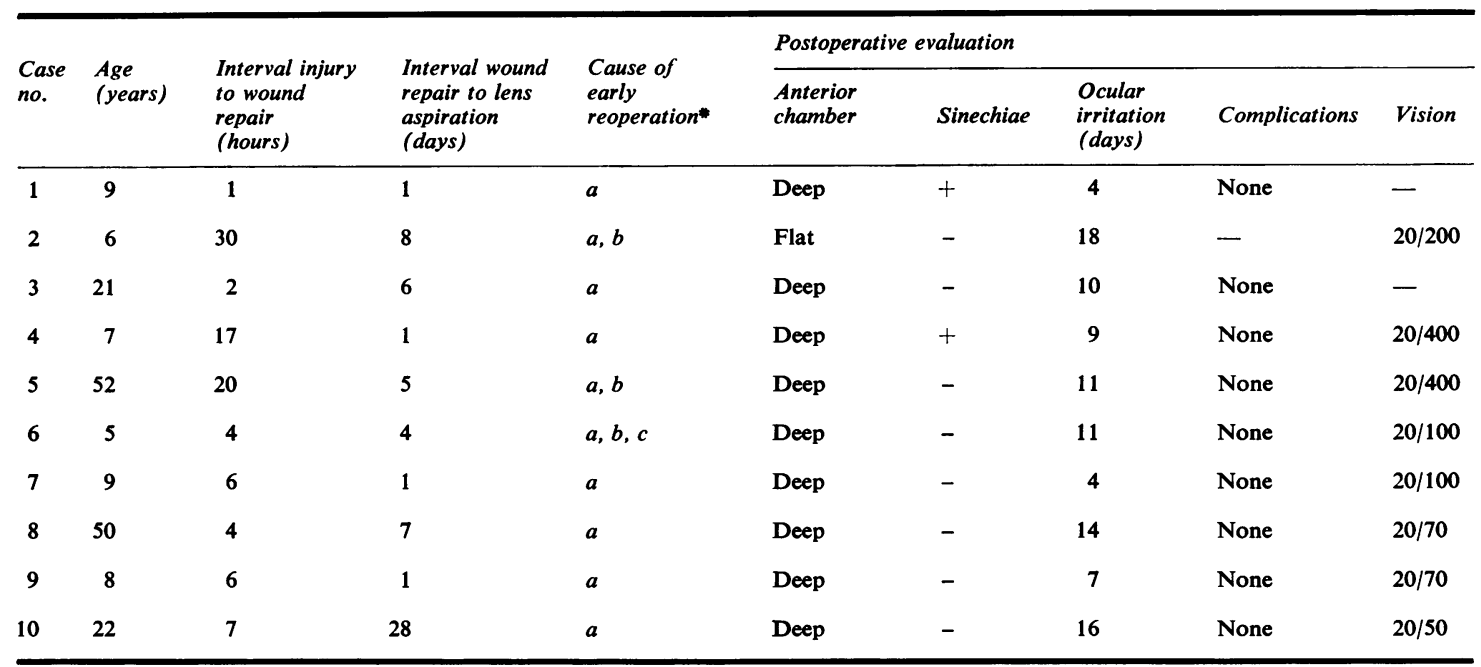

* (a) Intumescent lens. (b) Flat anterior chamber. (c) Glaucoma

cornea and extraction of a coexisting injured lens allows restoration of anterior segment physiology at the first operation. There is less need for manipulation, the postoperative irritative period and anterior chamber activity is shorter, complications due to the presence of an injured lens are prevented, the number of reoperations is reduced, and visual rehabilitation occurs earlier.

When analysing lens damage after perforating injuries of the eye several categories of damage may be established. One relates to the degree of lens damage and another relates to presence or absence of additional damage to other intraocular structures. Where the lens capsule is severely disrupted and flocculent lens material is dispersed in the anterior chamber there is a general consensus that all lens material should be removed at the initial repair of the injured globe (Roper-Hall, 1959; Muga, 1975; Eagling, 1976). Where capsular damage is smaller and the cataractous lens maintains its body and position, removal of the cataract at initial repair has not been always done or recommended. The problems associated with the presence of an injured lens in an eye that has had a perforating injury repaired have recently been emphasised. The cataract may become intumescent, and lens endothelial contact, flattening of the anterior chamber, or phacomorphic glaucoma may develop (Maul and Muga, 1977).

Phacoanaphylaxis occurs commonly after ocular trauma associated with lens capsule disruption. It may develop as early as 1 to 14 days, leading the

Table 3 Corneal wound repair and delayed aspiration of the lens

\begin{tabular}{|c|c|c|c|c|c|c|c|c|}
\hline \multirow{2}{*}{$\begin{array}{l}\text { Case } \\
\text { no. }\end{array}$} & \multirow{2}{*}{$\begin{array}{l}\text { Age } \\
\text { (years) }\end{array}$} & \multirow{2}{*}{$\begin{array}{l}\text { Interval injury } \\
\text { to wound } \\
\text { repair (hours) }\end{array}$} & \multirow{2}{*}{$\begin{array}{l}\text { Interval wound } \\
\text { repair to lens } \\
\text { aspiration (days) }\end{array}$} & \multicolumn{5}{|c|}{ Postoperative evaluation } \\
\hline & & & & $\begin{array}{l}\text { Anterior } \\
\text { chamber }\end{array}$ & Sinechiae & $\begin{array}{l}\text { Ocular irritation } \\
\text { (days) }\end{array}$ & Complications & Vision \\
\hline 1 & 22 & 72 & 44 & Deep & + & 16 & $\begin{array}{l}\text { Hyphaema, } \\
\text { vascularisation of lens }\end{array}$ & HM \\
\hline 2 & 12 & 16 & 48 & Deep & None & 7 & None & $20 / 100$ \\
\hline 3 & 2 & 4 & 45 & Deep & ++ & 15 & $\begin{array}{l}\text { Hyphaema, } \\
\text { vascularisation of lens }\end{array}$ & HM \\
\hline 4 & 13 & 47 & 47 & Deep & + & 16 & $\begin{array}{l}\text { Hyphaema, } \\
\text { vascularisation of } \\
\text { lens, fibrous lens } \\
\text { capsule remnants }\end{array}$ & HM \\
\hline 5 & 6 & 8 & 30 & Deep & + & 14 & $\begin{array}{l}\text { Fibrous lens capsule } \\
\text { remnants }\end{array}$ & $20 / 200$ \\
\hline
\end{tabular}


eye to a state of chronic inflammation unless a total surgical removal of the lens is performed (Perlman and Albert, 1977). The need for control of inflammation in the follow-up of cases with a perforating injury is particularly important to prevent the development of synechiae, fibrous strands, or fibrous ingrowth (Coles and Haik, 1972; Hutton $e t$ al., 1976). We may further add from the analysis of the present series that where lens surgery is deferred for a second operation several weeks later complications may be the rule.

Hyphaema occurred in 3 of 5 cases (see Table 3). Synechiae occurred very often, and the postoperative anterior chamber activity lasted 2 weeks. Ten cases in which lens aspiration was planned to be done 6 weeks after the initial repair of the corneal wound had to be operated on earlier because they developed an intumescence of the cataract soon after primary repair (see Table 2). In cases where cataract aspiration was done at initial repair of the globe postoperative complications were an exception, and ocular irritation and anterior chamber activity lasted only 5 to 6 days (see Table 1).

Removal of the lens in these cases was technically easy to perform. Transparency of the freshly lacerated cornea allowed optimal observation of anterior chamber structures. Anterior chamber depth, pupil area, and lens substance were perfectly seen through the microscope. Lens substance and capsular fragments offered no resistance to aspiration, and one could choose the intraocular structure to be manipulated, thus avoiding additional trauma during surgery.

Timing of lens surgery in our series influenced final results. Postoperative complications were less frequent and ocular irritation was shorter in duration in patients where simultaneous aspiration of the lens was performed as opposed to those reoperated upon later for removal of the cataract.

When associated damage of lens and other intraocular structures exist, the present trend in the management of such cases also favours a 'radical' primary surgical approach. This is specially valid for the presence of vitreous loss, since lens material mixed with vitreous fluid seems particularly devastating (Coleman and Franzen, 1974). Immediate removal of lens material and anterior vitrectomy has been recommended in such cases (Faulborn et al., 1977). However, we think in the face of our results and that of others (Eagling, 1975) that a major role in later complications is played by the presence of an injured lens in such cases.

In any case of injury the final result will depend not only upon the injury itself and the initial damage but on the chosen method of treatment as well as on later complications, which in some instance may be influenced by prophylactic treatment (RoperHall, 1969). We think that a definitive treatment should be attempted for the laceration of the cornea or sclera as well as for the laceration of intraocular structures at primary repair.

The authors are grateful to Elena Maria Korzenszky for secretarial assistance.

\section{References}

Adhikary, H. P., Taylor, P., and Fitzmaurice, D. J. (1976). Prognosis of perforating eye injury. British Journal of Ophthalmology, 60, 737-739.

Barraquer, J. (1975). Personal Communication at the $X$ Chilean Congress of Ophthalmology. Arica, Chile.

Coleman, D. J., and Franzen, L. A. (1974). Vitreous Surgery: Preoperative evaluation and prognostic value of ultrasonic display of vitreous hemorrhage. Archives of Ophthalmology, 92, 375-379.

Coles, W. H., and Haik, G. M. (1972). Vitrectomy in intraocular trauma. Its rationale and its indications and limitations. Archives of Ophthalmology, 87, 621-628.

Duke-Elder, Sir S. E. (1972). Injuries Part I. Mechanical injuries. System of Ophthalmology, Vol. 14, p. 351. Mosby: St. Louis.

Eagling, E. M. (1975). Perforating injuries involving the posterior segment. Transactions of the Ophthalmological Societies of the United Kingdom, 95, 335-339.

Eagling, E. M. (1976). Perforating injuries of the eye. British Journal of Ophthalmology, 60, 732-735.

Faulborn, J., Atkinson, A., and Oliver, D. (1977). Primary vitrectomy as a preventive surgical procedure in the treatment of severely injured eyes. British Journal of Ophthalmology, 61, 202-208.

Haik, G. M., and Coles, W. H. (1972). Associated injuries of the iris and the lens. In Intraocular Injuries, p. 54. Lea \& Febiger: Philadelphia.

Havener and Gloeokner (1969). Atlas of Diagnostic Techniques and Treatment of Intraocular Foreign Bodies, p. 34. Mosby: St. Louis.

Hutton, W. L., Snyder, W. B., and Vaiser, A. (1976). Vitrectomy in the treatment of ocular perforating injuries. American Journal of Ophthalmology, 81, 733-739.

Maul, E., and Muga, R. P. (1977). Anterior segment surgery early after corneal wound repair. British Journal of Ophthalmology, 61, 782-784.

Muga, R. P. (1975). Experiencia en el tratamiento de las heridas perforantes oculares. Archivos Chilenos de Oftalmología, 32, 73-78.

Perlman, E. M., and Albert, D. M. (1977). Clinically unsuspected phacoanaphylaxis after ocular trauma. Archives of Ophthalmology, 95, 244-246.

Reinecke, R. D., and Beyer, Ch. K. (1966). Lacerated corneas and prevention of sinechiae. American Journal of Ophthalmology, 61, 131-135.

Roper-Hall, M. J. (1959). The treatment of ocular injuries. Transactions of the Ophthalmological Societies of the United Kingdom, 79, 57-69.

Roper-Hall, M. J. (1969). A retrospective study of eye injuries. Ophthalmologica, 158, 12-27. 